\title{
Pesquisa artística - editorial
}

Martha Tupinambá de Ulhôa, Editora

A revista Art Research Journal - ARJ surgiu como consequência da construção do chamado QUALIS artístico pela área de artes ligada à Coordenação de Aperfeiçoamento de Pessoal de Nível Superior (CAPES), fundação do Ministério da Educação (MEC). ${ }^{1}$ O QUALIS artístico consiste em uma série de critérios externos, desenvolvidos por comissões de pesquisadores-artistas encarregados de avaliar a produção artística dos programas de pós-graduação em artes no Brasil. Nesse processo de avaliação foram adotados procedimentos comparáveis aos princípios consagrados pelos meios acadêmicos, ou seja, os mesmos critérios de qualificação indireta usados na construção do QUALIS bibliográfico vigente (na época a classificação dos periódicos por categoria e impacto). A preocupação na construção dos critérios é que sejam claros o bastante para permitir a formação de consenso intersubjetivo entre os pesquisadores artistas e, ao mesmo tempo, sejam compreensíveis pelas demais áreas de avaliação da CAPES.

No processo de atribuição do QUALIS artístico não é considerada a qualidade intrínseca do produto, mas seu contexto de realização e difusão. A intenção é valorizar a articulação da pesquisa acadêmica de pós-

\footnotetext{
${ }^{1}$ Este texto se baseia nos documentos da área de artes publicados no sítio da CAPES, bem como na reflexão sobre a especificidade da pesquisa em artes. Me responsabilizo, enquanto editora do ARJ por sua autoria, e agradeço as discussões e contribuições de vários colegas, entre os quais destaco Antônia Bezerra Pereira e Maria Beatriz de Medeiros.
} 
graduação com a criação artística. Assim, o QUALIS artístico não avalia a produção do artista individual, mas, em havendo linhas de pesquisa ligadas à criação ou prática artística no programa de pós-graduação, estima a proporção de docentes-artistas-pesquisadores produzindo arte qualificada. No âmbito da CAPES são os programas de pós-graduação e não os indivíduos que são avaliados.

O artista certamente não precisa de uma formação universitária para exercer sua prática criativa. No entanto, ao optar pela docência em nível superior, e, principalmente ao se dedicar à formação de pessoal para atuar nesse nível, ele ou ela assume o compromisso de dialogar com a comunidade de artes e com a comunidade acadêmica como um todo.

O grande diferencial entre a formação do artista pelos métodos tradicionais (o aprendizado por imitação e treinamento individual sob a tutoria de um mestre) e a formação do artista na universidade é a pesquisa. E nesse contexto, a pesquisa em artes na academia exige a atuação em um sistema que permita a produção, a troca, a parceria, a discussão e a disseminação do conhecimento produzido. Especialmente no domínio da pós-graduação em artes stricto sensu, valoriza-se a produção artística que tenha vínculo temático, conceitual ou metodológico com a pesquisa acadêmica.

Resta discutir e consolidar o que seja esta "pesquisa" em artes. Não só uma delimitação, sempre provisória, do objeto "arte", mas, principalmente as implicações que esta natureza imprevisível possa ter em termos metodológicos e teóricos. O objeto artístico, sendo único, nem sempre pode ser definido a priori; ele vai sendo construído enquanto o artista vai aprendendo a lidar com seus materiais. Às vezes, até a própria ideia que está por trás da concepção "teórica" do artista só fica clara a posteriori, depois da obra acabada.

Se o objeto não pode ser delimitado a priori - a não ser de forma provisória, pelo fato de o próprio artista professar uma vertente estética ou usar materiais e técnicas específicas - o mesmo pode-se dizer de 
hipóteses, de referencial teórico, de apresentação final do produto. É bom lembrar, que no caso da pesquisa-criação na universidade, no contexto dos cursos acadêmicos stricto sensu, tratam-se de dois produtos, um texto e uma obra, ambos publicáveis e arquiváveis.

O produto artístico apresentado na forma de performance presencial ou por registro audiovisual rende conhecimento tácito, compreensível para o grupo ou comunidade que compartilha seus códigos semânticos. Uma obra de arte diferenciada vai ser propositora por ir além das maneiras mais divulgadas de fazer arte. Por outro lado, não há como negar que o processo artístico ao ser descrito e interpretado através de um texto escrito sofre redução. A arte atravessa todos os sentidos e seus sentidos pois jamais há sentido único para a arte - não podem ser fixados pela linguagem escrita que é incapaz de abrager sua totalidade.

Um artigo, uma tese ou dissertação sobre arte é apenas um recorte interpretativo sobre algo mais complexo e, sobretudo, polissêmico. Por esta razão há que se insistir que, no caso de pesquisa artística, o produto artístico seja disponibilizado publicamente na sua forma mais integral, de preferência por um link para algum site estável, aberto e não comercial.

O grande diferencial entre a pesquisa na área de artes e na área científica, mesmo nas ciências sociais e humanas - cujos manuais de metodologia servem de modelo para os cursos onde nossos pós-graduandos aprendem sobre projetos de pesquisa e escrita acadêmica - é conseguir certo distanciamento de um objeto com o qual temos, por enculturação enquanto artistas práticos, uma relação visceral. Daí que o mais difícil é estabelecer uma "questão" de pesquisa, pois ela pode só ficar clara quando estamos dando por finalizada a investigação.

O paradoxo é que mesmo quando se trata de algo "concreto", como na crítica de arte (que lida com repertórios específicos, obras artísticas já prontas) ou na história da arte (que aborda artistas ou tradições artísticas específicas, localizáveis no tempo e no espaço) não há como fugir de uma metodologia artesanal, exploratória e imersa nas particularidades do 
objeto ou processo artístico em estudo. Arte é ao mesmo tempo um objeto histórico (inserido em um contexto temporal ou geográfico) e estético (com transcendência e valor intrínsecos relativos). Por isso arte se explica com arte, ao fazer sentido por comparação numa cadeia de objetos ou obras artísticas.

Uma história da arte feita do ponto de vista da História é diferente de uma história da arte escrita do ponto de vista da Arte, pois o objeto "arte" não é apenas um documento - embora possa ser tornado um para efeitos de tratamento analítico - mas, sobretudo um evento/objeto estético. Assim, enquanto historiadores de ofício escrevem sobre identidade e organização sócio-política usando a arte como ilustração (numa vertente explicativa), historiadores da arte escrevem sobre estilo e se preocupam com processos (numa vertente interpretativa, talvez mais filosófica). E, ao construir um "método artístico" comentam o funcionamento dos processos criativos ou artístico-interpretativos por uma comparação fundamentada (o mais coerente e consistente possível) com outros processos criativos ou artístico-interpretativos vigentes (ou seja, reconhecidos como legítimos pela comunidade artístico-acadêmica).

A pesquisa em artes é uma área do conhecimento relativamente recente no meio acadêmico. Os conservatórios e escolas de belas artes só foram incorporados à universidade em meados do século XX. No Brasil, apenas na década de 1990, aparecem os programas de doutorado em artes cênicas, artes visuais e música. Como não são cursos profissionais, mas acadêmicos, existe a exigência legal (a pós-graduação no país é regida por leis federais) da existência de um documento escrito (dissertação ou tese) ao lado do produto artístico (quando a linha de pesquisa envolve criação ou prática - algumas linhas são, por conta de seu objeto, de pesquisa histórica ou sistemática).

Não há como ensinar a ser criativo. Arte (no sentido de originalidade e criação), assim como ciência não é algo ensinável. Pode-se apenas insistir sobre a necessidade de se procurar conhecer profundamente as 
linguagens artísticas e de se informar sobre como os artistaspesquisadores estão lidando com delimitação do objeto, relação sujeitoobjeto, objetividade-subjetividade, prática e teoria, entre outros assuntos. Textos já publicados no número anterior de ARJ começaram a mapear algumas dessas questões. No número atual, precedidos por um texto sobre práxis e reflexão e outro sobre laboratórios teatrais, temos alguns exemplos de como lidar com a pesquisa artística por vários ângulos, na dança, no teatro, nas artes visuais, na música. A totalidade dos artigos emerge da reflexão sobre a prática artística.

No artigo de abertura, A arte da pesquisa em artes, a filósofa Kathleen Coessens - utilizando as metáforas do binóculo, do prisma e do quarto de espelhos - comenta as características da pesquisa artística, refletindo sobre as noções de experiência e de ação; teoria e teorização experimental; reflexão e refletividade.

A seguir, Marco De Marinis escreve sobre Pesquisa, experimentação e criação em teatro no século XXI, onde analisa os laboratórios teatrais dos artistas pesquisadores Decroux, Grotowski e Barba, esclarecendo noções de progresso, desenvolvimento, descoberta e demonstração na pesquisa teatral.

Gilbertto Prado, em Projetos recentes do Grupo Poéticas Digitais, apresenta as experimentações Des/uz de 2010, Amoreiras de 2010/12 e Encontros de 2012, conduzidas pelo grupo de professores artistas, pesquisadores e estudantes do Departamento de Artes Plásticas da ECAUSP, ligados a instalação interativa, arte em rede e artemídia.

Cristina Capparelli Gerling, em Barcarola op. 60 de F. Chopin, trata da parceria entre intérpretes musicais e a musicologia cognitiva, tomando como estudo de caso o relato dos processos de memorização da peça emblemática do repertório pianístico. No processo, decisões tomadas durante a prática são transferidas para o ato da interpretação, sem engessar a performance musical, sempre renovada a cada apresentação. 
Ciane Fernandes no artigo intitulado Pesquisa Somático-Performativa busca configurar caminhos abertos de investigação criativa, contaminada pelo que denomina a natureza pulsante da cena. Considerando pesquisa como processo, experiência, integração, e transgressão, a autora se aproxima de uma metodologia autônoma, imprevisível e, por isso mesmo, coerente com a noção de pesquisa artística.

Marcia Strazzacappa trata de Imersões poéticas como processo de formação do artista-docente, um processo de pesquisa de/em arte, onde intervenções poético-acadêmicas são promovidos/provocados por um artista, integrando estudantes, docentes e pessoas da comunidade em processos de criação cênico-coreográfica.

Renato Ferracini e Antônio Flávio Alves Rabelo, no artigo Recriar sempre tomam como foco o trabalho do ator, refletindo sobre a questão da criatividade no espetáculo Café com Queijo, do LUME - Núcleo interdisciplinar de Pesquisas Teatrais da UNICAMP, em cartaz desde 1999. Usando o conceito de pensar com, os autores desenvolvem o texto a partir da fala das atrizes da peça Ana Cristina Colla e Raquel Scotti Hirson.

O número sobre Pesquisa Artística se encerra com o texto de Ivani Santana, De corpo presente na dança digital distribuída em rede, onde a autora argumenta a favor do embodiment do corpo remoto, posicionando-se contra os discursos de pós-humano, do desembodiment ou da desmaterialização do corpo na era digital.

Ainda que os próximos dois volumes do ARJ, previstos para 2015 e 2016, devam conter Dossiês dedicados à Música, Artes plásticas e Artes cênicas, nesta ordem, outros artigos originais oriundos de pesquisa de doutorado ou pós-doutorado em qualquer área de artes criativas podem ser submetidos a qualquer momento pelo sistema de fluxo contínuo. Ressaltamos que os textos enviados, quando apresentarem vínculo temático, metodológico ou conceitual com as linhas de pesquisa em poéticas criativas e práticas interpretativas serão particularmente benvindos. 